\title{
Atomic Absorption Spectroscopy Reveals Anomalous Transfer of Heavy Metal across a Water/1,2-DCE Interface
}

\author{
B. R. Silver* \\ Biophysical Chemistry Department, J. "Heyrovsky' Institute of Physical Chemistry of the CAS, \\ v. v. i., Dolejškova 2155/3, 18223 Prague 8, Czech Republic \\ *Corresponding author: barrymet@yahoo.com
}

Received 20/02/2019; accepted 10/04/2021

https://doi.org/10.4152/pea.2021390603

\begin{abstract}
Atomic absorption spectroscopy (AAS) of samples taken from the organic phase of a water/1,2-dichloroethane (1,2-DCE) interfacial electrochemical cell, rendered nonpolarizable by the tetraphenylarsonium common-ion, revealed significant transfer of heavy metal from the aqueous phase. Heavy metal concentration found within 1,2-DCE cannot be explained via ion pair formation between the metallic species and the commonion, nor by ion pair formation between the metallic species and the hydrophobic anion of the organic phase. Results suggest that metal may have been anomalously transferred into 1,2-DCE within water-in-oil droplets formed by spontaneous emulsification of the interfacial region.
\end{abstract}

Keywords: liquid/liquid, extraction, metal, non-polarizable and ITIES (interface between two immiscible electrolyte solutions).

\section{Introduction}

Our previous work [1-3] demonstrates that liquid/liquid interfaces can, under certain circumstances, spontaneously emulsify and produce sub-micron waterin-oil (w/o) droplets containing electrolytes of the aqueous phase. In this study, we extend the practical relevance of this phenomenon by the introduction of heavy metal cations into the aqueous phase, at a non-polarizable water/1,2-DCE interface. Heavy metal cations have very positive Gibbs free energies of ions transfer requiring complexation or large energy inputs to transfer from water into an organic phase [4].

We have found, using AAS, that significant amounts of heavy metal are transferred into the organic phase at a non-polarizable water/1,2-DCE interface. The liquid/liquid interface was rendered non-polarizable by the presence of the tetraphenylarsonium $(\mathrm{TPhAs}+)$ common ion.

The heavy metal concentration within the organic phase cannot be adequately explained by ion pair formation between the metallic species and the common ion, 
nor by ion pair formation between the metallic species and the hydrophobic anion of the organic phase.

Results suggest an anomalous heavy metal transfer across the interface within w/o droplets formed by spontaneous emulsification of the interfacial region between the aqueous and 1,2-DCE phases.

\section{Experimental details}

Highly purified, deionised water (DI, conductance: $<0.1 \mu \mathrm{S} \mathrm{cm}^{-1}$, GORO system, Czech Republic) was used to prepare aqueous solutions. 1, 2-dichloroethane (1,2DCE, 99\%), supplied by Fluka Analytical (Czech Republic), was used as-received to prepare organic solutions. Tetraphenylarsonium chloride (TPhAsCl, polarography grade) was supplied by Fluka (Czech Republic). Lithium chloride ( $\mathrm{LiCl})$, Zinc (II) chloride $\left(\mathrm{ZnCl}_{2}\right)$, cadmium (II) chloride $\left(\mathrm{CdCl}_{2}\right)$, copper (II) chloride $\left(\mathrm{CuCl}_{2}\right)$ and lead (II) chloride $\left(\mathrm{PbCl}_{2}\right)$, all $>99 \%$, were supplied by Sigma Aldrich (Czech Republic). Tetraphenylarsonium chloride (TPhAsCl, > 98\%) was supplied by Fluka (Czech Republic). Potassium nitrate $\left(\mathrm{KNO}_{3}\right)$ was supplied by LaChem (Czech Republic). Tetraphenylarsonium tetrakis(4chlorophenyl)borate (TPhAsTPBCl) was prepared via metathesis of $\mathrm{TPhAsCl}$ and KTPBCl from Sigma Aldrich (Czech Republic).

A cylindrical glass vessel, with a stop-cock at one end, contained a liquid/liquid interface formed by layering $2 \mathrm{~mL}$ of an aqueous phase (typically $20 \mathrm{mM}$ $\mathrm{TPhAsCl}$ with or without $5 \mathrm{mM} \mathrm{XCl}$, where $\mathrm{X}=\mathrm{Cu}, \mathrm{Zn}, \mathrm{Pb}$ or $\mathrm{Cd}$ ) on top of 2 $\mathrm{mL}$ of an organic phase (10 $\mathrm{mM} \mathrm{TPhAsTPBCl}$ in 1,2-DCE). The liquid/liquid interface was slightly convex and had approximately $1.54 \mathrm{~cm}^{2}$ in area. The vessel was sealed to prevent evaporation, and was left at room temperature for $2 \mathrm{~h}$ prior to sampling. Multiple apparatus (of the same geometry) enabled larger sampled volumes of the organic phase to be obtained.

Ten minutes prior to the end of the $2 \mathrm{~h}$ period, a flame sealed glass capillary was carefully inserted into the organic phase, through the aqueous phase. The organic phase was slowly stirred for $30 \mathrm{~s}$ to homogenize its volume before sampling. After stirring, the capillary was carefully retracted from the vessel.

Sampling (at the $2 \mathrm{~h}$ mark) involved partially opening the stop-cock and sampling an aliquot of the organic phase. This aliquot was immediately weighed to ascertain its volume. The aliquot was subsequently evaporated over boiling water. The residue was solubilized in DI water, and sonicated for 5 mins with intermittent aspiration/stirring with a pipette. The water-insoluble suspension was filtered (Whatman, grade 42) over a solution containing $2 \mathrm{~mL} 0.1 \mathrm{M} \mathrm{KPF}_{6}$, which resulted in a fine white precipitate. This precipitate was filtered out of the solution (Whatman, grade 42), and then evaporated over boiling water.

A feint dry white residue remained, which was resolubilized using $0.1 \mathrm{M} \mathrm{KNO}_{3}$ in $0.1 \mathrm{M} \mathrm{HNO}_{3}$ (termed "matrix", see Table 1). The volume of the matrix used for residue solubilization was the same as of that originally sampled/weighed at the beginning of the protocol.

When the aqueous phase contained only $20 \mathrm{mM} \mathrm{TPhAsCl}$, one was interested in measuring the water-soluble $\mathrm{TPhAs}^{+}$within the organic phase. In this case, after filtering out water-insoluble TPhAsTPBCl (containing no $\mathrm{KPF}_{6}$ ), the filtrate was 
evaporated and resolubilized using a volume of "matrix" equal to the volume of the organic phase first sampled.

Aqueous samples were analyzed with AAS (ContrAA700, Analytik Jena, Germany) in a flame atomization mode. A xenon-discharge lamp in "hot spot" mode was used as a continuous radiation source. High resolution spectra were monitored in close neighborhood to the analytical lines of the elements under study.

The "three pixels method" (3 central pixels of the analytical line) was used each time for evaluation. Arsenic absorbance was measured at $193.6960 \mathrm{~nm}$ in an acetylene/nitrous oxide flame $(210 \mathrm{~L} / \mathrm{h})$ using 3 replicates, during 3 seconds each. Results were averaged. Other elements were analyzed using one replicate in an acetylene/air flame. Specifically: cadmium $(50 \mathrm{~L} / \mathrm{h})$, at $228.8018 \mathrm{~nm}$, copper $(50$ $\mathrm{L} / \mathrm{h})$, at $324.7540 \mathrm{~nm}$, lead $(65 \mathrm{~L} / \mathrm{h})$, at $217.0005 \mathrm{~nm}$ and zinc $(50 \mathrm{~L} / \mathrm{h})$, at $213.8570 \mathrm{~nm}$.

Calibration standards were diluted as appropriate and were as follows: arsenic $1000 \pm 5 \mathrm{mg} / \mathrm{L}$ (Merck), cadmium 1000 $2 \mathrm{mg} / \mathrm{L}$ (Merck), copper $1000 \pm 2 \mathrm{mg} / \mathrm{L}$ (ČMI), lead 998 2 mg/L (Merck) and zinc $1002 \pm 2 \mathrm{mg} / \mathrm{L}$ (Merck).

\section{Results and discussion}

The water-soluble component concentrations found within harvested waterinsoluble organic phase fractions (via AAS) are listed within Table 1, for each treatment. Within the text, the term 'water-soluble $\mathrm{TPhAs}^{+}$' is used. This refers to $\mathrm{TPhAs}^{+}$found within harvested oil phase aliquots after TPhAsTPBCl and 1,2DCE removal (see experimental section and vide infra). AAS detected the presence of free metal atoms from atomized aqueous aliquots. The presence of water-soluble $\mathrm{TPhAs}^{+}$found within organic phase fractions was detected as arsenic (see experimental section).

Table 1. Concentration of constituents comprising the water-soluble fraction found within the oil phase via AAS.

\begin{tabular}{|c|c|c|}
\hline Aqueous Phase & $\begin{array}{c}{[\mathrm{TPhAs}+]} \\
\mu \mathrm{M}\end{array}$ & $\begin{array}{l}{[\mathbf{M} 2+]} \\
\boldsymbol{\mu} \mathbf{M}\end{array}$ \\
\hline Matrix & 0 & 0 \\
\hline no interface & 0.7 & 0 \\
\hline 20 mM TPhAsCl & 179.1 & 0 \\
\hline $20 \mathrm{mM}$ TPhAsCl + $5 \mathrm{mM} \mathrm{CuCl} \mathrm{l}_{2}$ & 338.7 & 1.9 \\
\hline $20 \mathrm{mM}$ TPhAsCl + $5 \mathrm{mM} \mathrm{ZnCl}_{2}$ & 369.7 & 13.8 \\
\hline $20 \mathrm{mM}$ TPhAsCl + $5 \mathrm{mM} \mathrm{PbCl}_{2}$ & 380.3 & 46.7 \\
\hline $20 \mathrm{mM}$ TPhAsCl $+5 \mathrm{mM} \mathrm{CdCl_{2 }}$ & 667.8 & 872.8 \\
\hline
\end{tabular}

Oil phases, corresponding to listed (Table 1) aqueous phases, comprised $10 \mathrm{mM}$ TPhAsTPBCl in 1,2-DCE. No precipitate was observed at the interface during the experiment. The organic phase lacked visual turbidity after $2 \mathrm{~h}$.

The 'no interface' condition (Table 1) lacked a corresponding aqueous phase, being comprised solely of an aliquot of $10 \mathrm{mM}$ TPhAsTPBCl in 1,2-DCE. This aliquot was processed in accordance with the extraction of the water-soluble component (see experimental section). 
The low arsenic concentration found for this treatment indicates that most of the water-insoluble component was successfully captured during filtration, leaving only a water-soluble component (if present) for AAS analysis. Arsenic concentrations, therefore, directly reflect concentrations (Table 1) of water-soluble $\mathrm{TPhAs}^{+}$found within organic phases after $2 \mathrm{~h}$.

A significant amount of water-soluble $\mathrm{TPhAs}^{+}$(likely, as $\mathrm{TPhAsCl}$, to maintain electroneutrality) was found within the organic phase, while the aqueous phase contained $\mathrm{TPhAs}^{+}$alone (as $20 \mathrm{mM} \mathrm{TPhAsCl}$ ). This observation is consistent with previous work $[1,3]$ which indicates that w/o droplets formed by spontaneous emulsification contain electrolytes of the aqueous phase. One, however, notes a large increase in $\mathrm{TPhAs}^{+}$concentration above this 'baseline', when the aqueous phase contained both metal (II) chloride and $\mathrm{TPhAsCl}$. The increase in $\mathrm{TPhAs}^{+}$ concentration was almost twice of that of the 'baseline', for most metal additions. The cadmium-containing treatment indicates an increase in $\mathrm{TPhAs}^{+}$concentration of almost four times of that of the 'baseline'.

The higher the metal concentration, the higher the concentration of water-soluble $\mathrm{TPhAs}^{+}$found within the organic phase. The concentration of metal found within the organic phase increased in the order $\mathrm{Cu}^{2+}<\mathrm{Zn}^{2+}<\mathrm{Pb}^{2+}<\mathrm{Cd}^{2+}$.

$\mathrm{TPhAs}^{+}$is a well-known analytical reagent for mercury, tin, cadmium and zinc determination [5]. Its usefulness is based on the formation of a precipitate between $\mathrm{TPhAs}^{+}$and anionic metal chlorocomplexes in a highly concentrated chloride solution. These sparingly soluble precipitates are extractable to organic solvents like chloroform $[6,7]$. Using cadmium as an example, the formation of several metal chlorocomplexes is possible, depending on chloride concentration [8], according to:

$$
\mathrm{Cd}^{2+}+\mathrm{nCl}^{-} \rightleftharpoons \mathrm{CdCl}_{\mathrm{n}}^{2-\mathrm{n}}(\text { with } \mathrm{n}=1,2,3 \text { or } 4)
$$

At a lower chloride concentration, found in experimental conditions in this study, the positively charged, water-soluble monochlorocomplex dominates and is very stable [9]. Due to its positive charge, one expects less interaction with the cationic $\mathrm{TPhAs}^{+}$species [7]. Specifically, in water (pH 7 and at $298.15 \mathrm{~K}$ ), $5 \mathrm{mM} \mathrm{Cd}^{2+}$, in the presence of $30 \mathrm{mM} \mathrm{Cl}^{-}$, will speciate as $2.84 \mathrm{mM} \mathrm{CdCl}^{+}$and as $1.91 \mathrm{mM} \mathrm{Cd}^{2+}$ [10]. In contrast, $5 \mathrm{mM} \mathrm{Cu}^{2+}$, in the presence of $30 \mathrm{mM} \mathrm{Cl}^{-}(\mathrm{pH} 7$ and 298.15K), will speciate as $\mathrm{Cu}(\mathrm{OH})_{2}{ }^{2+}(1.59 \mathrm{mM})$, and less so as $\mathrm{CuCl}^{+}(37 \mu \mathrm{M})$. Stability constants for $\mathrm{CdCl}^{+}$and $\mathrm{CuCl}^{+}$are (as log $\mathrm{K}$ ) 1.98 and 0.43, respectively [9].

The monovalent anionic chlorocomplex, for all metal treatments (from $5 \mathrm{mM}$ metal (II) chloride) listed within Table 1, exists at very low concentrations, under experimental conditions featured herein. For example [10]: $\mathrm{CuCl}_{3}^{-}$(47.69 pM), $\mathrm{ZnCl}_{3}{ }^{-}(0.16 \mu \mathrm{M}), \mathrm{PbCl}_{3}-(1.26 \mu \mathrm{M})$ and $\mathrm{CdCl}_{3}{ }^{-}(4 \mu \mathrm{M})$. Therefore, if these species were to be extracted into 1,2-DCE, via ion pair formation with $\mathrm{TPhAs}^{+}$, one should expect lower metal concentrations within 1,2-DCE than those found experimentally (Table 1).

Metal concentration found within 1,2-DCE (Table 1) follows the order of both the expected concentration order [10] of the cationic $\mathrm{XCl}^{+}$and anionic $\mathrm{XCl}_{3}{ }^{-}$species. Cationic monochlorocomplexes will, however, exist at higher concentrations within the aqueous phase than at those of the anionic monochlorocomplexes, for 
example: $\mathrm{CdCl}^{+}(2.84 \mathrm{mM}), \mathrm{PbCl}^{+}(1.68 \mathrm{mM}), \mathrm{ZnCl}^{+}(0.2 \mathrm{mM})$ and $\mathrm{CuCl}^{+}(0.04$ $\mathrm{mM})$.

The expected concentrations for the anionic metallic chlorocomplexes are far below than those found via AAS (Table 1). It is difficult to see how an extractable precipitate, or an ion pair, might form between two cationic species $\left(\mathrm{TPhAs}^{+}\right.$and $\mathrm{XCl}^{+}$). Furthermore, $\mathrm{TPBCl}^{-}$is known to assist the transfer of monovalent $\mathrm{Rb}^{+}$and $\mathrm{Ag}^{+}[11,12]$. It may be that $\mathrm{TPBCl}^{-}$ion pairs with the monovalent cationic metal chlorocomplex, although this would not explain how metal enters the watersoluble fraction found within the organic phase. This is because most of the waterinsoluble fraction was successfully captured on the filter paper, during sample analysis. An ion pair between $\mathrm{TPBCl}^{-}$and a monovalent metal chlorocomplex would be water-insoluble. Furthermore, this type of ion pair was not detected in previous detailed work under polarized conditions $[13,14]$.

Recent work $[3,15]$ has shown that non-polarizable liquid/liquid interfaces can undergo spontaneous emulsification, with the formation of w/o droplets containing aqueous phase electrolytes. We have previously found that the $\mathrm{TPhAs}^{+}$common ion enables emulsification at the water/1,2-DCE interface [3]. It is, therefore, possible that metal may be transferred into the 1,2-DCE within w/o droplets. This would explain both the presence of a water-soluble metal fraction and watersoluble $\mathrm{TPhAs}^{+}$found within 1,2-DCE via AAS.

\section{Conclusions}

AAS reveals that a water/1,2-DCE interface, rendered non-polarizable with the $\mathrm{TPhAs}^{+}$common-ion and an aqueous phase containing metal (II) chloride, enables significant amounts of heavy metal to be transferred into 1,2-DCE. Cadmium was transferred in an amount which exceeded all other metals. Metal concentration within 1,2-DCE was greater than the expected via ion pair formation between the anionic metal chlorocomplex and $\mathrm{TPhAs}^{+}$. Moreover, a hydrophobic ion pair between $\mathrm{TPBCl}^{-}$and a cationic metal chlorocomplex was considered unlikely. Results, therefore, suggest metal was anomalously transferred into 1,2-DCE within w/o droplets formed by spontaneous emulsification of an interfacial region between a nonpolarizable water/1,2-DCE interface.

\section{Acknowledgments}

The authors acknowledge technical advice and experimental guidance with AAS from Dr. Václav Červený (Analytical Chemistry Department, Charles University, Prague). The authors gratefully acknowledge funding from the Czech Science Foundation (project number 17-09980S). The authors declare no conflict of interest.

\section{References}

1. Mareček V. Electrochemical monitoring of the co-extraction of water with hydrated ions into an organic solvent. Electrochem Communic. 2018;88:5760. https://doi.org/10.1016/j.elecom.2018.01.017

2. Silver BR. Detection of water-in-oil droplet formation within an interfacial region formed by an aqueous/1, 2-dichloroethane interface using transient cell 
impedance measurements at a single high frequency. Russian J Electrochemistry. 2019;55(2):1-6. https://doi.org/10.1134/s1023193519020095

3. Silver BR, Holub K, Mareček V. Spontaneous emulsification at surfactantless liquid/liquid interfaces. J Electroanalyt Chem. 2017;805:91-7. https://doi.org/10.1016/j.jelechem.2017.10.027

4. Lagger G, Tomaszewski L, Osborne MD, et al. Electrochemical extraction of heavy metal ions assisted by cyclic thioether ligands. J Electroanalyt Chem. 1998;451(1-2):29-37. https://doi.org/10.1016/S0022-0728(97)00389-6

5. Willard HH, Smith GM. Tetraphenylarsonium chloride as an analytical reagent. Indust \& Eng Chem Analyt Edit. 1939;11(5):269-74. https://doi.org/10.1021/ac50133a014

6. Murphy J, Affsprung $H$. Extraction and determination of gold with tetraphenylarsonium chloride. Analyt Chem. 1961;33(12):1658-60. https://doi.org/10.1021/ac60180a016

7. Ueno K, Chang C. Solvent Extraction Studies on the Hydrochloric acidTetraphenylarsonium Chloride Chloroform System. Nippon Genshiryoku Gakkai-Shi. 1962;4(7).

8. Vanderzee CE, Dawson Jr HJ. The Stability Constants of Cadmium Chloride Complexes: Variation with Temperature and Ionic Strength. J American Chem Soc. 1953;75(22):5659-63. https://doi.org/10.1021/ja01118a056

9. Smith R, Martell A, Motekaitis R. Critically selected stability constants of metal complexes. NIST standard reference database. 2004;46:8.

10. Parkhurst DL, Appelo C. User's guide to PHREEQC (Version 2): A computer program for speciation, batch-reaction, one-dimensional transport, and inverse geochemical calculations. 1999.

11. Kontturi A, Kontturi K, Manzanares J, et al. Ion Pairing in the Analysis of Voltammetric Data at the ITIES: RbTPB and RbTPBCl in 1, 2-dichloroethane. Berichte der Bunsengesellschaft für physikalische Chemie. 1995;99(9):11316. https://doi.org/10.1002/BBPC.199500044

12. Caçote M, Pereira C, Tomaszewski L, et al. Ag+ transfer across the water/1, 2dichloroethane interface facilitated by complex formation with tetraphenylborate derivatives. Port Electrochim Acta. 2004;49(2):263-70. https://doi.org/10.1016/j.electacta.2003.08.008

13. Mastouri A, Peulon S, Bellakhal N, et al. M (II) transfer across a liquid-liquid microinterface facilitated by a complex formation with 8-Hydroxyquinoline: Application to quantification of $\mathrm{Pb}$ (II), $\mathrm{Cd}$ (II) and $\mathrm{Zn}$ (II) alone or in mixture in effluents. Port Electrochim Acta. 2014;130:818-25. https://doi.org/10.1016/j.electacta.2014.03.073

14. Mastouri A, Peulon S, Farcage D, et al. Perfect additivity of microinterface arrays for liquid-liquid measurements: Application to cadmium ions quantification. Port Electrochim Acta. 2014;120:212-8. DOI:10.1016/j.electacta.2013.12.034

15. Holub K, Samec Z, Mareček V. Role of water in the mechanism of the salt extraction to the organic solvent. Port Electrochim Acta. 2019;306:541-48. https://doi.org/10.1016/j.electacta.2019.03.096 